\title{
A chiral Mn(IV) complex and its supramolecular assembly: Synthesis, characterization and properties
}

\author{
CHULLIKKATTIL P PRADEEP, PANTHAPALLY S ZACHARIAS and SAMAR K DAS* \\ School of Chemistry, University of Hyderabad, Hyderabad 500 046, India \\ e-mail: skdsc@uohyd.ernet.in
}

MS received 24 January 2006; revised 30 June 2006

\begin{abstract}
The open air reaction of the chiral Schiff base ligand $\mathrm{H}_{2} \mathrm{~L}$, prepared by the condensation of Lphenylalaninol and 5-bromosalicylaldehyde, with $\mathrm{Mn}^{\mathrm{II}}\left(\mathrm{CH}_{3} \mathrm{COO}\right)_{2} \cdot 4 \mathrm{H}_{2} \mathrm{O}$ yielded dark brown complex $\left[\mathrm{Mn}^{\mathrm{IV}} \mathrm{L}_{2}\right] \cdot 0 \cdot 5 \mathrm{DMF}$ (1). Compound 1 was characterized by elemental analysis, IR, UV-visible, CD and EPR spectroscopy, cyclic voltammetry and room temperature magnetic moment determination. Singlecrystal X-ray analysis revealed that compound 1 crystallises in the monoclinic $P 2_{1}$ space group with six mononuclear $\left[\mathrm{Mn}^{\mathrm{IV}} \mathrm{L}_{2}\right]$ units in the asymmetric unit along with three solvent DMF molecules. In the crystal structure, each Mn(IV) complex, acting as the building unit, undergoes supramolecular linking through $\mathrm{C}-\mathrm{H} \cdots \mathrm{O}$ bonds leading to an intricate hydrogen bonding network.
\end{abstract}

Keywords. Synthesis; characterization; crystal structure; chiral $\mathrm{Mn}(\mathrm{IV})$ complex; C-H$\cdots \mathrm{O}$ hydrogen bonding interaction.

\section{Introduction}

The chemistry of higher valent manganese, especially $\mathrm{Mn}(\mathrm{IV})$, has been the subject of considerable research for the last couple of decades. ${ }^{1}$ This is because of the importance of higher valent manganese in various biological systems like the OEC (oxygen evolving complex) of photosystem II. $^{2}$ In addition to their biological roles, $\mathrm{Mn}(\mathrm{IV})$ systems are also important with respect to asymmetric catalysis. ${ }^{3}$ The role of chiral $\mathrm{Mn}(\mathrm{IV})$ species in the catalytic asymmetric epoxidation of olefins has been the subject of some current publications. ${ }^{4}$

Tridentate ligands derived from substituted salicylaldehydes and chiral amino alcohols are among the 'priviledged' ligand templates, generally employed for various asymmetric transformations. ${ }^{5}$ Complexes of these ligand systems with metal ions such as $\mathrm{Ti}^{4+}$, $\mathrm{V}^{5+}, \mathrm{Cu}^{2+}$ etc. have been successfully applied for various aymmetric tansformations as chiral catalysts. ${ }^{6}$ However, the manganese chemistry of such ligand systems has not been explored much. Recently, we have reported our preliminary studies on manganese chemistry of chiral amino alcohols based Schiff base ligands. ${ }^{7}$ In continuation of our previous work, we report herein the synthesis, structural cha-

*For correspondence racterization and properties of a chiral $\mathrm{Mn}(\mathrm{IV})$ mononuclear complex $\left[\mathrm{Mn}^{\mathrm{IV}} \mathrm{L}_{2}\right] \cdot 0 \cdot 5 \mathrm{DMF}(\mathbf{1})$; the relevant chiral Schiff base ligand system $\mathrm{H}_{2} \mathrm{~L}$ is described in scheme 1 .

\section{Experimental}

\subsection{Materials and methods}

L-Phenylalaninol $\quad[(S)-(-)-2-A m i n o-3-p h e n y l-1-p r o-$ panol] and 5-bromosalicylaldehyde were purchased from Lancaster and used as received. TBAP (tetrabutylammonium perchlorate), used as the supporting electrolyte in electrochemical measurement, was purchased from Acros India. Solvents were purified by standard methods. All other chemicals were of<smiles>OC[C@H](Cc1ccccc1)NCc1cc(Br)ccc1O</smiles>

Scheme 1. Schematic representation of $\mathrm{H}_{2} \mathrm{~L}$. The chiral centre is represented by an asterisk. 
analytical grade and were used without further purification.

Microanalytical $(\mathrm{C}, \mathrm{H}, \mathrm{N})$ data were obtained with a Flash EA 1112 Series CHNS Analyzer. A Shimadzu 3101-PC UV/Vis/NIR spectrophotometer was used to record the electronic spectra. Infrared spectra were recorded on $\mathrm{KBr}$ pellets with a Jasco-5300 FTIR spectrophotometer. ${ }^{1} \mathrm{H}$ spectra of the ligand $\mathrm{H}_{2} \mathrm{~L}$ in $\mathrm{CDCl}_{3}$ solution were recorded on a Bruker $400 \mathrm{MHz}$ spectrometer using $\mathrm{Si}\left(\mathrm{CH}_{3}\right)_{4}$ as internal standard. Room temperature solid state magnetic susceptibility was measured by using a Sherwood Scientific magnetic susceptibility balance. A CH-Instruments model 620A electrochemical analyzer was used for cyclic voltammetric experiment on an acetonitrile solution of the complex 1 containing TBAP as supporting electrolyte. The three-electrode measurement was carried out at $298 \mathrm{~K}$ under a dinitrogen atmosphere with a platinum disc working electrode, a platinum wire auxiliary electrode and a $\mathrm{Ag} / \mathrm{AgCl}$ reference electrode. CD spectra were measured with a Jasco J-810 spectropolarimeter. EPR spectra were recorded on a Jeol JES-FA200 spectrometer.

\subsection{Synthesis of ligand $\mathrm{H}_{2} \mathrm{~L}$}

L-Phenylalaninol $\quad[(S)-(-)-2$-amino-3-phenyl-1-propanol] $(0 \cdot 151 \mathrm{~g}, 1 \mathrm{mmol})$ and 5-bromosalicylaldehyde $(0.201 \mathrm{~g}, 1 \mathrm{mmol})$ were stirred together in methanol $(15 \mathrm{ml})$ for $1 \mathrm{~h}$ at room temperature. The resulting yellow solution was filtered and the filtrate was kept for 2 days in an open beaker for slow evaporation. Yellow precipitate of $\mathrm{H}_{2} \mathrm{~L}$ thus obtained was washed with hexane and dried at room temperature. Yield was $0.284 \mathrm{~g}(85 \%)$.

Analysis: Calc. for $\mathrm{C}_{16} \mathrm{H}_{16} \mathrm{NO}_{2} \mathrm{Br}: \mathrm{C}, 57 \cdot 5 ; \mathrm{H}, 4 \cdot 83$; $\mathrm{N}, 4 \cdot 19 \%$. Found: C, $57 \cdot 1 ; \mathrm{H}, 4 \cdot 77 ; \mathrm{N}, 4 \cdot 11 \%$.

FT-IR (KBr): 3364, 1633, 1599, 1570, 1510, 1477, $1365,1275,1186,1072,1035,968,925,825,750$, $704,625,557,472 \mathrm{~cm}^{-1}$.

${ }^{1} \mathrm{H} \mathrm{NMR}\left(400 \mathrm{MHz}, \mathrm{CDCl}_{3}\right): \delta 2.95\left(\mathrm{~m}, 2 \mathrm{H}, \mathrm{CH}_{2^{-}}\right.$ $\mathrm{Ph}), 3.55(m, 1 \mathrm{H}, \mathrm{CH}), 3.82\left(\mathrm{~m}, 2 \mathrm{H}, \mathrm{CH}_{2}-\mathrm{OH}\right), 6.86$ $(d, 1 \mathrm{H}, \mathrm{Ar}$, ortho to $\mathrm{OH}), 7 \cdot 13-7 \cdot 404(m, 7 \mathrm{H}, \mathrm{Ar})$, $8.01(s, 1 \mathrm{H}, \mathrm{HC}=\mathrm{N})$.

UV/Vis $\left(\mathrm{CH}_{3} \mathrm{CN}\right): \lambda_{\max }, \mathrm{nm}\left(\varepsilon, \mathrm{M}^{-1} \mathrm{~cm}^{-1}\right): 326$ (4747), 255 (12120).

\subsection{Synthesis of complex 1}

$\mathrm{Mn}\left(\mathrm{CH}_{3} \mathrm{COO}\right)_{2} \cdot 4 \mathrm{H}_{2} \mathrm{O}(0.245 \mathrm{~g}, 1 \mathrm{mmol})$ was added to a methanolic solution $(15 \mathrm{ml})$ of ligand $\mathrm{H}_{2} \mathrm{~L}$
$(0.334 \mathrm{~g}, 1 \mathrm{mmol})$. The mixture was allowed to stir at room temperature in air for $12 \mathrm{~h}$. The dark brown solution obtained was evaporated to dryness using a rotavapor and vacuum pump. The solid, thus obtained, was dissolved in dichloromethane, washed twice with water and once with brine solution (using a separating funnel), and then dried over anhydrous $\mathrm{Na}_{2} \mathrm{SO}_{4}$. The resulting dark brown solution, on slow evaporation, gave the brown microcrystalline solid, 1. Yield was $0.525 \mathrm{~g}(73 \%)$.

Analysis: Calc. for $\mathrm{C}_{32} \mathrm{H}_{28} \mathrm{~N}_{2} \mathrm{O}_{4} \mathrm{Br}_{2} \mathrm{Mn}$ : C, 53.43; H, 3.92 ; N, 3.89\%. Found: C, 53.60; H, 4.01; N, 3.95\%. FT-IR (KBr): 1610, 1520, 1452, 1369, 1300, 1170, 1045, 798, 746, 700, 644, 574, 520, $455 \mathrm{~cm}^{-1}$.

UV/Vis $\left(\mathrm{CH}_{3} \mathrm{CN}\right): \lambda_{\max }, \mathrm{nm}\left(\varepsilon, \mathrm{M}^{-1} \mathrm{~cm}^{-1}\right): 550 \mathrm{~nm}$ (sh, 1430), $470 \mathrm{~nm}(s h, 2719), 404(5753) \mathrm{nm}, 345$ (sh, 7008), 287 (sh, 17200).

\section{$2.4 \quad X$-ray crystallography}

Data were measured at 298(2) $\mathrm{K}$ on a Bruker SMART APEX CCD area detector system $[\lambda(\mathrm{Mo}-$ $\mathrm{K} \alpha)=0.71073 \AA$ ] , graphite monochromator, 2400 frames were recorded with an $\omega$ scan width of $0.3^{\circ}$ each for $10 \mathrm{~s}$, crystal-detector distance $60 \mathrm{~mm}$, collimator $0.5 \mathrm{~mm}$. Data reduction was done by SAINTPLUS $^{8}$ structure solution using SHELXS-97 ${ }^{9}$ and refined using SHELXH-97. ${ }^{10}$ All non-hydrogen atoms were refined anisotropically. Hydrogen atoms were introduced at calculated positions and included in the refinement riding on their respective parent atoms. Additional details of the data collection parameters and refinement are collected in table 1 . The absolute configuration of the compound was successfully determined by refining the Flack parameter $(0 \cdot 005(5)) .^{11}$ The final Fourier difference synthesis showed minimum and maximum peaks of -0.672 and $+0.988 e \AA^{-3}$. CCDC-294223 contains the supplementary crystallographic data for complex 1 . This can be obtained free of charge on application to the Director, CCDC, 12 Union Road, Cambridge CB21EZ, UK (fax: +44 1223336 033; e-mail: deposit@ccdc.cam.ac.uk or www: http://www.ccdc.cam.ac.uk).

\section{Results and discussion}

The chiral ligand $\mathrm{H}_{2} \mathrm{~L}$ was synthesized in good yields as a yellow solid by the Schiff base condensation of 5-bromosalicylaldehyde with the chiral amino alcohol L-phenylalaninol. Open air reaction of a methanolic 
solution of the ligand with $\mathrm{Mn}\left(\mathrm{CH}_{3} \mathrm{COO}\right)_{2} \cdot 4 \mathrm{H}_{2} \mathrm{O}$ in $1: 1$ ratio yielded the corresponding $\mathrm{Mn}(\mathrm{IV})$ complex as a dark brown solid. Atmospheric oxygen is the possible oxidizing agent here, and oxidizes the $\mathrm{Mn}$ (II) salt to the corresponding $\mathrm{Mn}$ (IV) complex. The presence of phenolato and alcoholato groups in the ligand facilitates the oxidation of $\mathrm{Mn}$ (II) to $\mathrm{Mn}(\mathrm{IV})$.

The IR spectrum of the Schiff base ligand, $\mathrm{H}_{2} \mathrm{~L}$, exhibits a broad band at $3364 \mathrm{~cm}^{-1}$ due to the intramolecularly hydrogen bonded $v(\mathrm{OH})$. This band is absent in the complex revealing the deprotonation of the $\mathrm{OH}$ group during complexation. Also the Schiff base exhibits $v(\mathrm{C}=\mathrm{N})$ band at $1633 \mathrm{~cm}^{-1}$, which shifts to lower energy by $\sim 20 \mathrm{~cm}^{-1}$ in the complex indicating nitrogen coordination of the ligand.

Single crystals of $\mathbf{1}$ suitable for X-ray analysis were grown from dimethylformamide (DMF) solution by the slow evaporation method. The molecule crystallizes in the monoclinic chiral space group $P 2_{1}$. The asymmetric unit contains six mononuclear manganese complexes along with three DMF solvent molecules. In each of these mononuclear units, present in the asymmetric unit, $\mathrm{Mn}$ is hexacoordinated with $\mathrm{N}_{2} \mathrm{O}_{4}$ coordination sphere. Two tridentate ONO donor ligands satisfy the coordination sites of the

Table 1. Crystallographic data for $\mathbf{1 .}$

\begin{tabular}{ll}
\hline Emp. formula & $\mathrm{C}_{32} \mathrm{H}_{28} \mathrm{Br}_{2} \mathrm{MnN}_{2} \mathrm{O}_{4} \cdot 0 \cdot 5 \mathrm{DMF}$ \\
FW & $755 \cdot 87$ \\
Crystal system & Monoclinic \\
Space group & $P 2_{1}$ \\
$\lambda(\AA)$ & $0 \cdot 71073$ \\
$a(\AA)$ & $19 \cdot 677(6)$ \\
$b(\AA)$ & $21 \cdot 013(7)$ \\
$c(\AA)$ & $24 \cdot 573(8)$ \\
$\beta\left({ }^{\circ}\right)$ & $105 \cdot 123(6)$ \\
$V\left(\AA^{3}\right)$ & $9808(6)$ \\
$Z$ & 6 \\
$\mu\left(\mathrm{mm}^{-1}\right)$ & $2 \cdot 890$ \\
$\rho_{\text {calcd }}\left(\mathrm{gcm}^{-3}\right)$ & $1 \cdot 536$ \\
$T\left({ }^{\circ} \mathrm{C}\right)$ & 25 \\
Scan type & $\omega$ \\
Independent reflns & 115256 \\
& $\left(R_{\text {int }}=0 \cdot 0834\right)$ \\
Obsd. reflns. $[F>4 \sigma(F)]$ & 46128 \\
No. of parameters & 2352 \\
$S_{\text {gof }}$ on $F^{2}$ & $0 \cdot 929$ \\
$R_{1}^{a}[F>4 \sigma(F)]$ & $0 \cdot 0563$ \\
$w R_{2}^{\mathrm{b}}$ & $0 \cdot 1018$ \\
Absolute structure & $0 \cdot 005(5)$ \\
parameter & \\
Largest diff. peak and & $0 \cdot 988$ and $-0 \cdot 672$ \\
hole $\left(\mathrm{e} \AA^{-3}\right)$ & \\
\hline
\end{tabular}

metal in a meridional manner. Each ligand contains deprotonated phenolic and alcoholic groups along with an imine nitrogen. The overall coordination geometry around the $\mathrm{Mn}$ in each complex can be considered roughly as distorted octahedron (figure 1). Four oxygen atoms can be taken as constituting a square plane about which the two imine nitrogens are situated at axial trans positions. The $\mathrm{Mn}-\mathrm{O}_{\mathrm{phe}}$, $\mathrm{Mn}-\mathrm{O}_{\mathrm{alk}}$, and $\mathrm{Mn}-\mathrm{N}_{\mathrm{imi}}$ distances vary in the range 1.878(5)-1.913(5), 1.835(5)-1.862(5) and 1.964(6)$1.989(6) \AA$ respectively. The average $\mathrm{Mn}-\mathrm{O}_{\text {phe }}$ (1.896(5)), Mn- $\mathrm{O}_{\text {alk }}(1.849(5))$ and $\mathrm{Mn}-\mathrm{N}_{\text {imi }}(1.976(6))$ distances observed are comparable to those reported for $\mathrm{Mn}(\mathrm{IV})$ complexes with similar ligation. ${ }^{\mathrm{lb}}$ Selected bond lengths and angles are given for a representative mononuclear unit in table 2.

All six mononuclear Mn(IV) complexes, present in the asymmetric unit, are involved in hydrogenbonding interactions in forming an intricate threedimensional hydrogen-bonding network. These six $\mathrm{Mn}(\mathrm{IV})$ complexes can be named as $\mathrm{Mn}(1), \mathrm{Mn}(2)$, $\operatorname{Mn}(3), \operatorname{Mn}(4), \operatorname{Mn}(5)$ and $\operatorname{Mn}(6)$ units. In the asymmetric unit, $\operatorname{Mn}(1)$ and $\operatorname{Mn}(2)$ complexes are

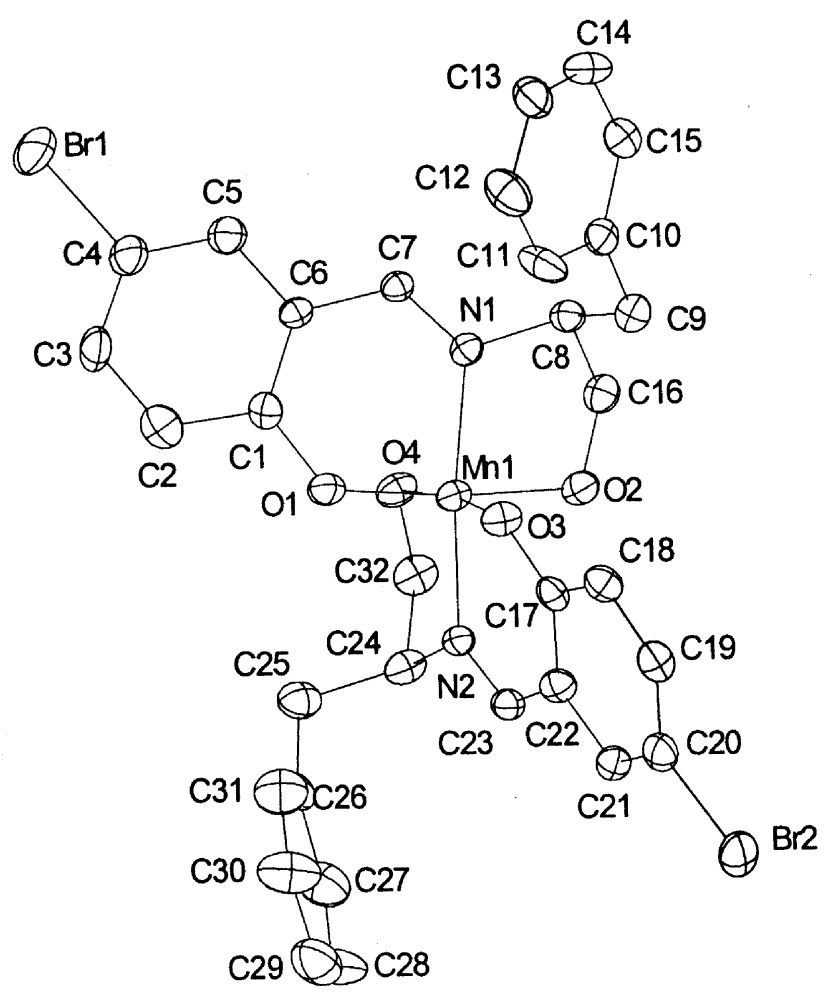

Figure 1. Thermal ellipsoidal plot of the title Mn(IV) complex 1 with atom labelling scheme. One representative complex, among six Mn(IV) complexes, present in the asymmetric unit has been taken. 

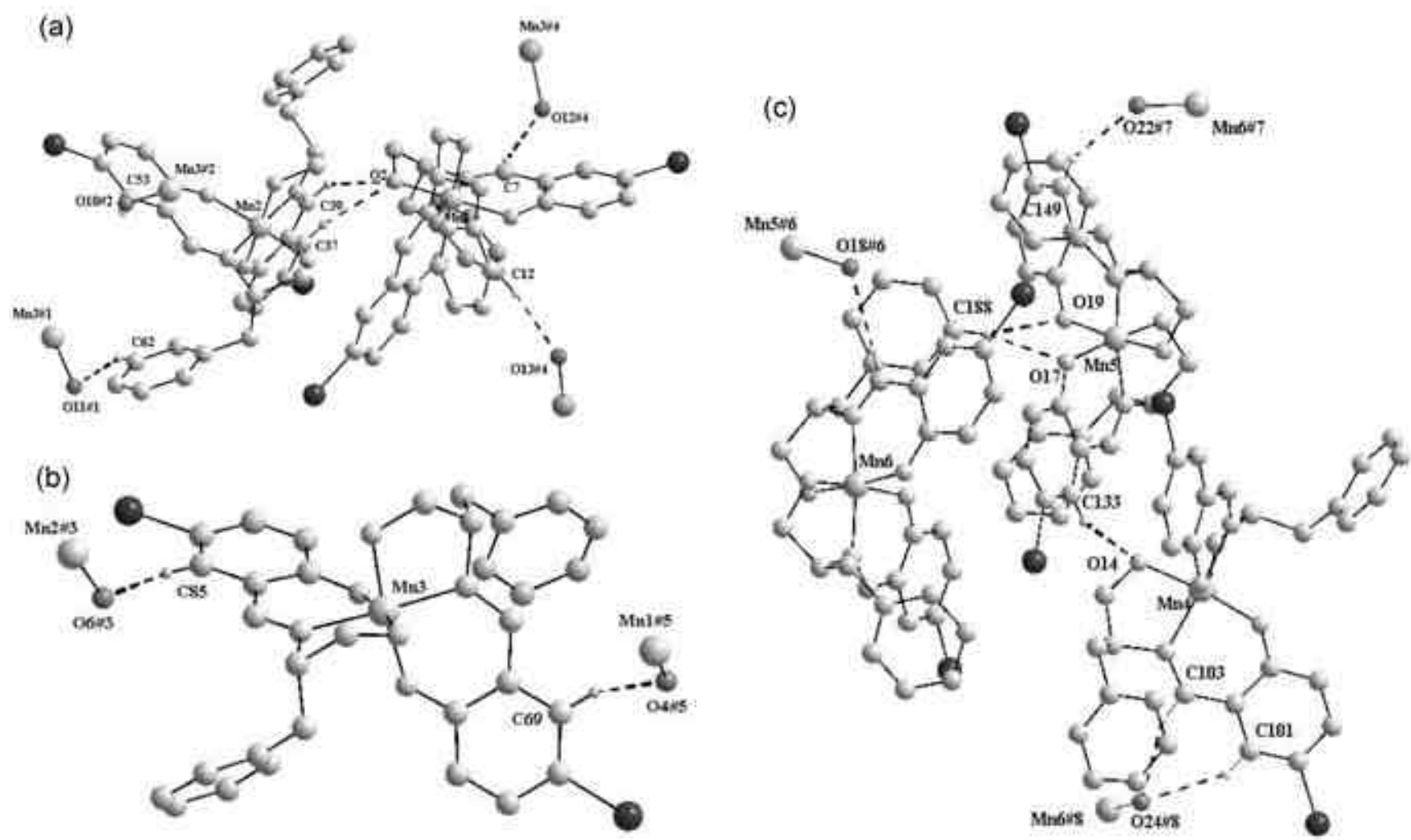

Figure 2. (a) $\mathrm{Mn}(1)-\mathrm{Mn}(2)$ hydrogen-bonded dimer formed in the asymmetric unit and its surrounding hydrogenbonding interactions with other Mn complexes. (b) Hydrogen-bonding interactions of the Mn(3) complex with other two Mn complexes. (c) Mn(4)-Mn(5)-Mn(6) hydrogen-bonded trimer formed in the asymmetric unit and its surrounding hydrogen-bonding interactions with other Mn complexes.

Table 2. Selected bond lengths $(\AA)$ angles $\left(^{\circ}\right)$ for a representative Mn(IV) unit.

\begin{tabular}{lrlr}
\hline $\mathrm{Mn}(1)-\mathrm{O}(1)$ & $1 \cdot 892(5)$ & $\mathrm{Mn}(1)-\mathrm{N}(2)$ & $1 \cdot 989(5)$ \\
$\mathrm{Mn}(1)-\mathrm{O}(2)$ & $1 \cdot 859(5)$ & $\mathrm{N}(1)-\mathrm{C}(7)$ & $1 \cdot 287(7)$ \\
$\mathrm{Mn}(1)-\mathrm{N}(1)$ & $1 \cdot 981(5)$ & $\mathrm{N}(2)-\mathrm{C}(23)$ & $1 \cdot 287(8)$ \\
$\mathrm{Mn}(1)-\mathrm{O}(3)$ & $1 \cdot 913(5)$ & $\mathrm{O}(1)-\mathrm{C}(1)$ & $1 \cdot 334(8)$ \\
$\mathrm{Mn}(1)-\mathrm{O}(4)$ & $1 \cdot 839(5)$ & $\mathrm{O}(3)-\mathrm{C}(17)$ & $1 \cdot 303(8)$ \\
& & & \\
$\mathrm{O}(2)-\mathrm{Mn}(1)-\mathrm{O}(1)$ & $173 \cdot 7(2)$ & $\mathrm{O}(1)-\mathrm{Mn}(1)-\mathrm{N}(1)$ & $91 \cdot 0(2)$ \\
$\mathrm{O}(4)-\mathrm{Mn}(1)-\mathrm{O}(3)$ & $171 \cdot 7(2)$ & $\mathrm{O}(3)-\mathrm{Mn}(1)-\mathrm{N}(1)$ & $95 \cdot 0(2)$ \\
$\mathrm{O}(4)-\mathrm{Mn}(1)-\mathrm{O}(2)$ & $92 \cdot 2(2)$ & $\mathrm{O}(2)-\mathrm{Mn}(1)-\mathrm{N}(2)$ & $87 \cdot 6(2)$ \\
$\mathrm{O}(4)-\mathrm{Mn}(1)-\mathrm{O}(1)$ & $89 \cdot 9(2)$ & $\mathrm{O}(4)-\mathrm{Mn}(1)-\mathrm{N}(2)$ & $84 \cdot 0(2)$ \\
$\mathrm{O}(2)-\mathrm{Mn}(1)-\mathrm{O}(3)$ & $92 \cdot 9(2)$ & $\mathrm{O}(1)-\mathrm{Mn}(1)-\mathrm{N}(2)$ & $98 \cdot 5(2)$ \\
$\mathrm{O}(1)-\mathrm{Mn}(1)-\mathrm{O}(3)$ & $85 \cdot 7(2)$ & $\mathrm{O}(3)-\mathrm{Mn}(1)-\mathrm{N}(2)$ & $89 \cdot 7(2)$ \\
$\mathrm{O}(2)-\mathrm{Mn}(1)-\mathrm{N}(1)$ & $83 \cdot 1(2)$ & $\mathrm{N}(1)-\mathrm{Mn}(1)-\mathrm{N}(2)$ & $169 \cdot 7(2)$ \\
$\mathrm{O}(4)-\mathrm{Mn}(1)-\mathrm{N}(1)$ & $92 \cdot 1(2)$ & & \\
\hline
\end{tabular}

hydrogen-bonded to form an $\mathrm{Mn}(1)-\mathrm{Mn}(2)$ hydrogen-bonded dimer (figure 2a). This is formed by acceptance of the $\mathrm{C}-\mathrm{H}$ protons of the $\mathrm{Mn}(2)$ complex by the $\mathrm{O}(2)$ oxygen of the $\mathrm{Mn}(1)$ complex. The $\mathrm{Mn}(3)$ complex, which is not hydrogen-bonded to any asymmetric unit components, is attached to the
$\mathrm{Mn}(1)$ and $\mathrm{Mn}(2)$ units via two respective $\mathrm{C}-\mathrm{H} \cdots \mathrm{O}$ bonds (figure 2b). $\mathrm{Mn}(4), \operatorname{Mn}(5)$ and $\operatorname{Mn}(6)$ units are linked via hydrogen-bonds in the asymmetric unit, forming a hydrogen-bonded trimer (Mn(4)$\mathrm{Mn}(5)-\mathrm{Mn}(6))$ as shown in figure 2c. The formation of this trimer can be described by the bifurcated 
Table 3. Hydrogen-bonding parameters $\left(\AA,^{\circ}\right)$ for $\mathbf{1}$.

\begin{tabular}{lcclcc}
\hline $\mathrm{D} \mathrm{H} \cdots \mathrm{A}$ & $\mathrm{D}-\mathrm{H}$ & $\mathrm{H} \cdots \mathrm{A}$ & $\mathrm{D} \cdots \mathrm{A}$ & $\mathrm{D}-\mathrm{H} \cdots \mathrm{A}$ & Symmetry operator of A \\
\hline $\mathrm{C}(7) \mathrm{H}(7) \cdots \mathrm{O}(12)$ & $0 \cdot 93$ & $2 \cdot 57$ & $3 \cdot 413(8)$ & $151 \cdot 6$ & $1-x, 0 \cdot 5+y, 1-z$ \\
$\mathrm{C}(12) \mathrm{H}(12) \cdots \mathrm{O}(13)$ & $0 \cdot 93$ & $2 \cdot 37$ & $3 \cdot 294(10)$ & $172 \cdot 7$ & $1-x, 0 \cdot 5+y, 1-z$ \\
$\mathrm{C}(37) \mathrm{H}(37) \cdots \mathrm{O}(2)$ & $0 \cdot 93$ & $2 \cdot 62$ & $3 \cdot 371(9)$ & $138 \cdot 6$ & $x, y, z$ \\
$\mathrm{C}(39) \mathrm{H}(39) \cdots \mathrm{O}(2)$ & $0 \cdot 93$ & $2 \cdot 40$ & $3 \cdot 223(8)$ & $147 \cdot 4$ & $x, y, z$ \\
$\mathrm{C}(53) \mathrm{H}(53) \cdots \mathrm{O}(10)$ & $0 \cdot 93$ & $2 \cdot 46$ & $3 \cdot 237(9)$ & $141 \cdot 6$ & $-x, 0 \cdot 5+y, 1-z$ \\
$\mathrm{C}(62) \mathrm{H}(62) \cdots \mathrm{O}(11)$ & $0 \cdot 93$ & $2 \cdot 47$ & $3 \cdot 316(10)$ & $151 \cdot 0$ & $1-x,-0 \cdot 5+y, 1-z$ \\
$\mathrm{C}(69) \mathrm{H}(69) \cdots \mathrm{O}(4)$ & $0 \cdot 93$ & $2 \cdot 41$ & $3 \cdot 193(8)$ & $141 \cdot 7$ & $-x,-0 \cdot 5+y, 1-z$ \\
$\mathrm{C}(85) \mathrm{H}(85) \cdots \mathrm{O}(6)$ & $0 \cdot 93$ & $2 \cdot 53$ & $3 \cdot 392(9)$ & $155 \cdot 2$ & $1-x,-0 \cdot 5+y, 2-z$ \\
$\mathrm{C}(101) \mathrm{H}(101) \cdots \mathrm{O}(24)$ & $0 \cdot 93$ & $2 \cdot 51$ & $3 \cdot 367(9)$ & $153 \cdot 3$ & $x, y, z+y, 2-z$ \\
$\mathrm{C}(103) \mathrm{H}(103) \cdots \mathrm{O}(24)$ & $0 \cdot 93$ & $2 \cdot 59$ & $3 \cdot 433(8)$ & $151 \cdot 1$ & $-x,-0 \cdot 5+y, 2-z$ \\
$\mathrm{C}(133) \mathrm{H}(133) \cdots \mathrm{O}(14)$ & $0 \cdot 93$ & $2 \cdot 63$ & $3 \cdot 471(9)$ & $151 \cdot 0$ & $-x, 0 \cdot 5+y, 2-z$ \\
$\mathrm{C}(149) \mathrm{H}(149) \cdots \mathrm{O}(22)$ & $0 \cdot 93$ & $2 \cdot 41$ & $3 \cdot 259(9)$ & $151 \cdot 8$ & $x, y, z$ \\
$\mathrm{C}(183) \mathrm{H}(183) \cdots \mathrm{O}(18)$ & $0 \cdot 93$ & $2 \cdot 55$ & $3 \cdot 296(8)$ & $137 \cdot 4$ & $156 \cdot 1$ \\
$\mathrm{C}(188) \mathrm{H}(188) \cdots \mathrm{O}(17)$ & 0.93 & $2 \cdot 42$ & $3 \cdot 288(11)$ & & \\
\hline
\end{tabular}

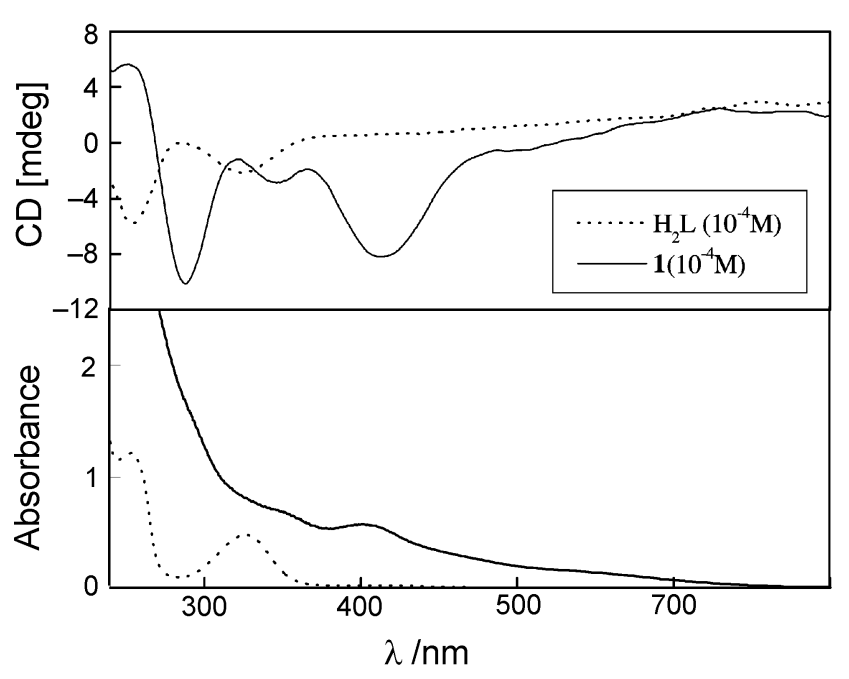

Figure 3. Circular dichroism (above) and electronic (below) spectra of $\mathbf{1}$ and ligand $\mathrm{H}_{2} \mathrm{~L}$ in acetonitrile solutions.

$\mathrm{C}-\mathrm{H} \cdots \mathrm{O}$ hydrogen-bonding interactions between $\mathrm{Mn}(5)$ and $\mathrm{Mn}(6)$ complexes, followed by the interaction of the $\operatorname{Mn}(5)$ complex with the $\operatorname{Mn}(4)$ complex. Interestingly, this trimer, formed in the asymmetric unit, is additionally hydrogen-bonded to three surrounding $\mathrm{Mn}$ complexes (namely $\mathrm{Mn}(5), \mathrm{Mn}(6)$ and $\mathrm{Mn}(6))$ in the crystal structure. The hydrogenbonded dimer is further hydrogen-bonded to four Mn complexes (three $\mathrm{Mn}(3)$ and one $\mathrm{Mn}(4)$ ). These interactions result in the formation of a multifaceted hydrogen-bonding network. The packing of these manganese complexes results in the formation of helical channels when viewed down to the crystallographic $a$ axis. We believe that the chirality of the complex $\left[\mathrm{Mn}^{\mathrm{IV}} \mathrm{L}_{2}\right]$ plays an important role in forming such helical channels. The relevant $\mathrm{C}-\mathrm{H} \cdots \mathrm{O}$ hydrogen bonding parameters are described in table 3 .

Electronic spectra of the ligand $\mathrm{H}_{2} \mathrm{~L}$ show prominent peaks at 326 and $255 \mathrm{~nm}$ which can be assigned to transitions of the intramolecularly hydrogen-bonded salicylidenimino chromophore. Cotton effects of negative sign are observed for these bands in the corresponding circular dichroism spectra which can be correlated with the absolute configuration of the amino alcohol moiety used. ${ }^{12}$

Electronic and circular dichroism spectra of the complex 1 show red shift in the band position compared to the bands of the free ligand $\mathrm{H}_{2} \mathrm{~L}$ (figure 3 ). In the visible region, an octahedral $\mathrm{Mn}(\mathrm{IV}) d^{3}$ system is expected to exhibit two electronic absorption bands due to $d-d$ transitions viz. ${ }^{4} A_{2 g} \rightarrow{ }^{4} T_{2 g}$ and ${ }^{4} A_{2 g} \rightarrow{ }^{4} T_{1 g}$. A shoulder at $470 \mathrm{~nm}$ and a broad band at $550 \mathrm{~nm}$ observed for the complex 1 in acetonitrile solution are probably due to the $d-d$ transitions. The rather high intensity of these bands may be due to the strong UV tail in the visible region. The intense bands observed in the high energy portions of the absorption spectrum of $\mathbf{1}$ can be assigned to chargetransfer transitions judging from their molar extinction coefficients values. The electronic spectrum of $\mathbf{1}$ is in good agreement with those reported for the hydroxyl-rich mononuclear Mn(IV) Schiff base complexes in the literature. ${ }^{1 \mathrm{~m}}$

Redox properties of compound $\mathbf{1}$ were investigated by cyclic voltammetry at a platinum disc working electrode in acetonintrile solution using a silversilver chloride reference electrode. The cyclic voltammogram of complex $\mathbf{1}$ is showin in figure 4 . A 
quasi-reversible one-electron reduction of the $\mathrm{Mn}(\mathrm{IV})$ complex occurs at $E_{1 / 2}=-0.44 \mathrm{~V}$ with $\Delta E_{p}=110 \mathrm{mV}$ $\left[E_{1 / 2}=1 / 2 E_{p a}+E_{p c}\right), \Delta E_{p}=E_{p a}-E_{p c}, E_{p a}$ and $E_{p c}$ are anodic and cathodic peak potentials respectively]. The negative reduction potential shown by this complex demonstrates the stability of this complex in acetonitrile solution and also the ability of doubly deprotonated Schiff base ligand to stabilize the higher oxidation state of manganese.

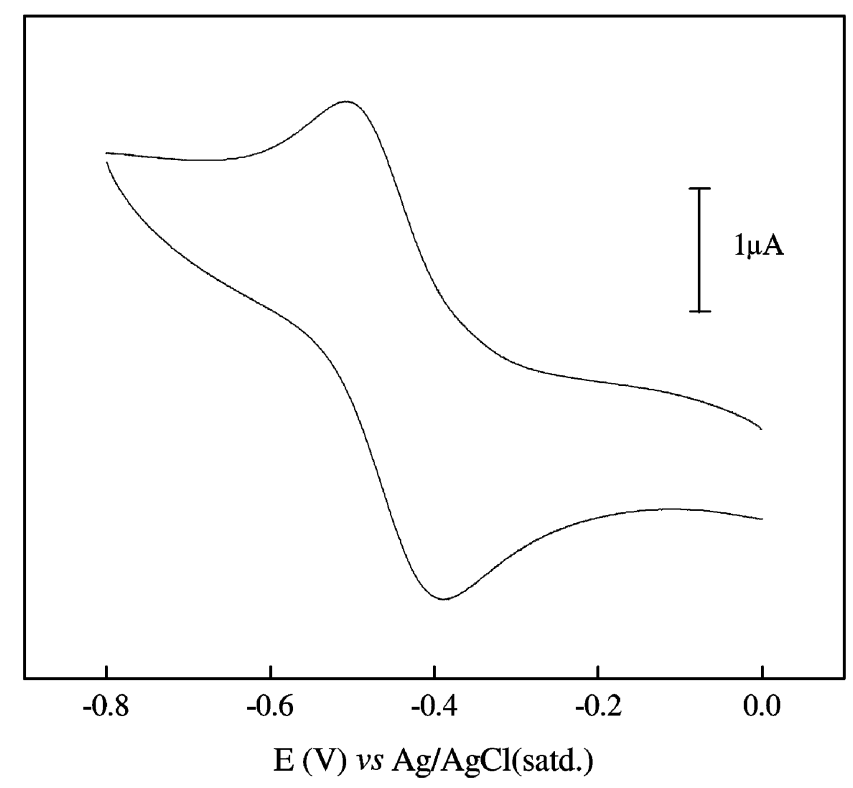

Figure 4. Cyclic voltammogram of $\sim 10^{-3} \mathrm{M}$ acetonitrile solution of 1 at $298 \mathrm{~K}\left(0.1 \mathrm{M}\right.$ TBAP, scan rate $100 \mathrm{mVs}^{-1}$, platinum disc working electrode).

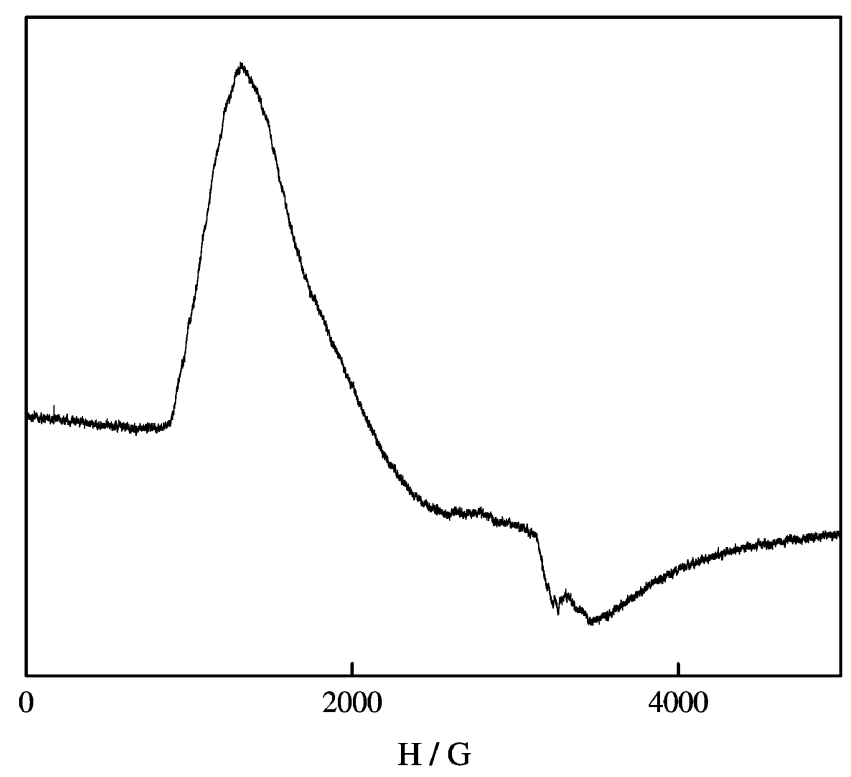

Figure 5. ESR spectrum of $\mathbf{1}$ in methanol solution at liquid nitrogen temperature.
The X-band ESR spectrum of $\mathbf{1}$ obtained from frozen methanol solution is shown in figure 5 . The major feature of the spectrum is a weak unresolved resonance at $g \sim 2$ and a strong signal at $g \sim 4$. In the crystal field of $O_{h}$ symmetry, manganese(IV) (a $d^{3}$ system) has a ${ }^{4} A_{2 g}$ ground state which affords an isotropic resonance at $g \sim 2$. In an axially distorted complex with the zero-field splitting parameter $D$ larger as compared to the microwave quantum, two main resonances are expected: a strong one near $g=4$ and a weaker one near $g=2$. The low temperature ESR spectrum of $\mathbf{1}$ thus corresponds to a large axial zero-field splitting parameter, i.e. $2 D>>h v{ }^{13}$

Room temperature magnetic moment of the complex 1 is found to be $4.00 \mathrm{BM}$ which indicate an $S=3 / 2$ spin state in the complex. This experimental $\mu_{\text {eff }}$ value clearly indicates that the complex $\mathbf{1}$ is an $\mathrm{Mn}(\mathrm{IV})$ system in complete agreement with X-ray and other characterization results.

\section{Conclusions}

A new chiral mononuclear Mn(IV) complex has been synthesized and structurally characterized. This complex belongs to the limited number of structurally characterized manganese complexes of chiral amino alcohol based ligand systems. The chirality of complex 1 has been confirmed by circular dichroism studies, while the oxidation state $(+4)$ of manganese is supported by electrochemical and ESR studies. We have shown that each Mn(IV) complex can act as a building unit to construct an intricate three-dimensional hydrogen-bonding network via $\mathrm{C}-\mathrm{H} \cdots \mathrm{O}$ hydrogen bonds in the crystal structure.

\section{Acknowledgements}

This work was supported by Department of Science and Technology, Government of India. CPP thanks the University Grants Commission, Govt. of India for a fellowship. Infrastructural support from the UGC (UPE programme) and the DST (national X-ray diffractometer facility) is also acknowledged.

\section{References}

1. John R P, Sreekanth A, Kurup M R P and Fun H-K 2005 Polyhedron 24 601; Weyhermuller T, Paine T $\mathrm{K}$, Bothe E, Bill E and Chaudhuri P 2002 Inorg. Chim. Acta 337 344; Rajendiran T M, Kampf J W and Pecoraro V L 2002 Inorg. Chim. Acta 339 497; Perez- 
Lourido P, Romero J, Rodriguez L, Garcia-Vazquez J A, Castro J, Sousa A, Dilworth J R and Nascimento O R 2002 Inorg. Chem. Commun. 5 337; Asada H, Ozeki M, Fujiwara M and Matsushita T 1999 Chem. Lett. 525; Mikuriya M, Jie D, Kakuta Y and Tokii T 1993 Bull. Chem. Soc. Jpn. 66 1132; Hart R O C, Bott S G, Atwood J L and Cooper S R 1992 J. Chem. Soc., Chem. Commun. 894; Saadeh S M, Lah M S and Pecoraro V L 1991 Inorg. Chem. 30 8; Dutta S, Basu P and Chakravorty A 1991 Inorg. Chem. 30 4031; Chandra S K, Choudhury S B, Ray D and Chakravorty A $1990 \mathrm{~J}$. Chem. Soc., Chem. Commun. 474; Chandra S K, Basu P, Ray D, Pal S and Chakravorty A 1990 Inorg. Chem. 29 2423; Deplano P, Trogu E F, Bigoli F and Pellingheli M A 1987 J. Chem. Soc., Dalton Trans. 2407; Kessissoglou D P, Li X, Butler W M and Pecoraro V L 1987 Inorg. Chem. 26 2487; Kessissoglou D P, Butler W M and Pecoraro V L 1986 J. Chem. Soc., Chem. Commun. 1253; Pavacik P S, Huffman J C and Christou G 1986 J. Chem. Soc., Chem. Commun. 43; Tirant M and Smith T D 1986 Inorg. Chim. Acta 1215

2. Pecoraro V L (ed.) 1992 Manganese redox enzymes (New York: VCH); Yachandra V K, DeRose V J, Latimer M J, Mukerji I, Sauer K and Klein M P 1993 Science 260 675; Manchanda R, Brudvig G W and Crabtree R H 1995 Coord. Chem. Rev. 144 1; Debus R J 1992 Biochim. Biophys. Acta 1102 269; Cole J, Yachandra Y K, Guiles R D, McDermott A E, Britt R D, Dexheimer S L, Sauer K and Klein M P 1987 Biochim. Biophys. Acta 890 395; Zimmermann J L and Rutherford A W 1986 Biochemistry 25395

3. Jacobsen E N, Pfaltz A and Yamamoto H (eds) 1999 Comprehensive asymmetric catalysis (New York:
Springer-Verlag); Katsuki T 2000 Catalytic asymmetric synthesis (ed.) I Ojima (New York: VCH)

4. Bryliakov K P, Kholdeeva O A, Vanina M P and Talsi E P 2002 J. Mol. Catal. A178 47; Adam W, Mock-Knoblauch C, Saha-Möller C R and Herderich M 2000 J. Am. Chem. Soc. 1229685

5. Owens T D, Souers A J and Ellman J A 2003 J. Org. Chem. 68 3; Jacobsen E N 2000 Acc. Chem. Res. 33 421

6. Vicario J L, Badía D, Carrillo L, Reyes E and Etxebarria J 2005 Curr. Org. Chem. 9 219; Lu G, Li Y-M, Li X-S and Chan A S C 2005 Coord. Chem. Rev. 249 1736; Pu L and Yu H-B 2001 Chem. Rev. 101 757; Ager D J, Prakash I and Schaad D R 1996 Chem. Rev. 96835

7. Pradeep C P, Htwe T, Zacharias P S and Das S K 2004 New J. Chem. 28 735; Pradeep C P, Zacharias P S and Das S K 2005 Polyhedron 241410

8. Software for the CCD Detector System, Bruker Analytical X-Ray Systems Inc., Madison, WI, 1998

9. Sheldrick G M 1997 SHELXS-97, Program for structure solution, University of Göttingen, Germany

10. Sheldrick G M 1997 SHELXH-97, Program for crystal structure analysis, University of Göttingen, Germany

11. Flack H D 1983 Acta Crystallogr. A39 876

12. Smith H E, Padilla B G, Neergaard J R and Chen F-M 1979 J. Org. Chem. 441690

13. McGarvey B R 1966 In Transition metal chemistry (ed.) R L Carlin (New York: Marcel Dekker) vol. 3, p 89; Pederson E and Toftlund H 1974 Inorg. Chem. 13 1603; Bradley D C, Copperthwaite R G, Cotton S A, Sales K D and Gibson J F 1973 J. Chem. Soc., Dalton Trans. 191 